\title{
Regulatory aspects of workplace drug testing in Europe
}

\author{
Anya Pierce*
}

\begin{abstract}
Workplace drug testing in Europe is governed by a patchwork of legislation - or lack of it. Other difficulties are caused by language, currency and a host of other factors, including the difficulty in defining 'safety critical'. The European Workplace Drug Testing Society's (EWDTS) history and objectives are briefly outlined. Some of the problems peculiar to testing in Europe are discussed. Finally, some of the legislation in the different countries is described. Copyright $\odot 2012$ John Wiley \& Sons, Ltd.
\end{abstract}

Keywords: workplace drug testing; EWDTS; legislation

\section{Introduction}

Workplace drug testing (WDT) is widespread in the United States, where it began. It is performed in government work, in all areas of transport and in many of the top companies. In Europe, WDT is on the increase. ${ }^{[1-4]}$ However, although the European Union (EU) is a market of nearly 500 million people compared to the USA's 305 million, it is by no means a homogenous market. The EU is made up of 27 different countries. Of these, only 17 are in the Eurozone - although the currency is also used in a further five non-EU countries (Montenegro, Andorra, Monaco, San Marino, and the Vatican) and in the disputed territory of Kosovo. The four biggest economies are Germany with 82 million people, France with 65 million, the United Kingdom with 61 million, and Italy with 58 million. WDT is mainly performed in the United Kingdom and Sweden, neither of which is in the Eurozone.

\section{The European Workplace Drug Testing Society (EWDTS)}

In 1998 , it was realized by many of those involved that, while the USA, Australia, and New Zealand had enforceable WDT directives, there was no regulation in Europe. A conference was organized in Stockholm, Sweden entitled Drug Testing at Workplace and, from this conference the European Workplace Drug Testing Group (EWDTG) was formed on 31 March 1998. The initial core group comprised one to two members from each EU country (it was smaller then) plus Norway and Switzerland. The group reformed as a formal society (EWDTS) with by-laws and an elected board, which initially comprised people with a laboratory background but thereafter representing a much broader range of disciplines. The EWDTS has published guidelines for sample collection and testing in urine, hair, and oral fluid. ${ }^{[5-7]}$

The mission of the EWDTS is to ensure that WDT in Europe is performed to a defined quality standard and in a legally secured way, and to provide an independent forum for all aspects of WDT. The EWDTS objectives are to:

- Be the source of expertise on WDT in Europe

- Be the primary advisor to the European Commission

- Develop literature and website
- Organize courses for medical review officers (MROs)

- Organize courses for sample collectors

The EWDTS guidelines are recognized by the European co-operation for Accreditation (EA). ${ }^{[8]}$

\section{Some general considerations}

\section{Matrices}

The main matrices used are urine, blood, breath, hair, oral fluid, and sweat. As an alternative, some companies are testing surfaces in the workplace such as bathrooms or phones as it is not as invasive and the surfaces belong to the company.

Urine is still the most commonly used matrix, though oral fluid and hair testing are on the increase. Breath alcohol usually still requires urine or blood confirmation.

The EWDTS needs to update its guidelines quickly. Many companies are increasingly using the guidelines they need be reviewed regularly. More than one matrix is now often used. The range of drugs abused can also change.

\section{Safety critical}

The majority of legislation that recommends random drug testing prescribes it in terms of safety critical areas. The actual definition of what can be defined as safety critical is very vague. The nuclear industry is generally agreed to be safety critical, as are transport, the military, and mining. Most also believe that the construction industry should be in this category but it is the one industry that does very little testing: one of the main excuses used is the problems with the extensive use of sub-contractors.

While patients would prefer to have their surgeons and physicians drug-free, the professions do not seem to feel that they need to be tested; neither do air traffic controllers. The police have different problems, because if they abuse

\footnotetext{
* Correspondence to: Anya Pierce, PPM Consultants Limited, 14 Bulford Business Park, Kilcoole, Co. Wicklow, Ireland.

E-mail: anya@iol.ie 
drugs they may be prosecuted, which is not the case for the general population.

Another debate concerns whether, if safety critical workers are tested, their co-workers should be, too. The Swedish court case, referred to below, seems to imply that they should.

\section{Other problems and traps for the unwary}

While the EWDTS guidelines are used by the EA, it would be preferable to have enforceable directives that operate throughout Europe and are the same in every country. In the absence of legislation, the guidelines need to be updated and expanded.

As was seen earlier, there are different laws in different countries. For example, small amounts of cannabis can be legally used in the Netherlands. There is also an increasing interest in the use of medical cannabinoids across Europe, particularly in the UK and Ireland.

In the USA, there is only one official language. A major problem in Europe is the huge variety of languages. As much WDT originates in the USA, many of the forms and explanations used are in English. The person being tested may not understand English, which can lead to severe miscommunication.

The date can also cause difficulties as in Europe the day/ month/year ( $d d / m m / y y)$ is typical whereas in the USA the format $\mathrm{mm} / \mathrm{dd} / \mathrm{yy}$ is used. It is therefore important to write the full date such as 8 January 2011.

Across Europe there are large differences in standards: livings standards, healthcare, and health and safety at work. Quality issues and laboratory accreditation are not the same for each country. There are also cultural differences: for example, most French and Nordic inhabitants take their vacations in the month of August so it is difficult to schedule testing in this month. Different public holidays create further problems.

In many cases, the initial screening test is performed in one country while the confirmation is done in another country. This can give rise to problems in collecting the specimens. The different processes used in the different laboratories and in the transport involved can make it easier for challenges from the legal community. This can all make it more difficult to have a clear chain of custody.

It is also generally more expensive to test for drugs in Europe. There are few economies of scale. Payments may be in different currencies which, with currency fluctuations - particularly at the moment - creates difficulties, with more bureaucracy and delays.

The lack of trained personnel is also problematic. While in some countries there are a few courses available for collectors, in many there are none. Collectors need training in their own language as they may miss important nuances if learning in a second language. In many countries occupational physicians take on the role of Medical Review Officer (MRO) but do not possess the necessary skills and training (and with the same language problem in arranging training).

In the USA, drug testing statistics are available but not so in Europe. There is very little reliable data and there is an aura of secrecy. Overall more openness is needed as well as pan-European directives on all aspects of testing from collections to the final report.

\section{Regulation outside Europe}

The USA, Australia and New Zealand have strict directives which must be observed.
USA

Drug tests in the USA can be divided into two general groups: federally and non-federally regulated testing. Drug testing guidelines and processes are established and regulated by the Substance Abuse and Mental Health Services Administration (SAMHSA). ${ }^{\text {[9] }}$ The Department of Transportation (DOT) also tests frequently with many of the top companies also testing randomly.

\section{Australia and New Zealand}

In Australia and New Zealand, the requirements for workplace drug and alcohol testing are stipulated in Australian Standards: ${ }^{[10]}$

- The Australian Urine Drug Testing Standard AS4308:2008

- The Australian Saliva Drug Testing Standard AS4760:2006

\section{Regulation in Europe}

In Europe, any regulation must conform to the Convention for the Protection of Human Rights and Fundamental Freedoms (commonly known as the European Convention on Human Rights (ECHR)) which provides for a person's right to privacy, which states that everyone has the right to his private and family life, his home and his correspondence and that public authorities must not interfere with the exercise of this right 'except such as is in accordance with the law and is necessary in a democratic society in the interests of national security, public safety or the economic well-being of the country, for the prevention of disorder or crime, for the protection of health or morals, or for the protection of the rights and freedoms of others' ${ }^{[11]}$

The legislation in the various countries is summarized below. ${ }^{[9]}$

\section{Finland}

The 2004 Act on Workplace Drug Testing (759/2004) ss.7-8 allows WDT which must be paid for by the employer. It is only allowed in defined circumstances, where intoxication or addiction may endanger life, health, national or traffic safety, security of information in the public interest, or business or professional confidentiality.

Before the law was enacted, the armed forces were tested but after its enacting, this was deemed illegal.

\section{Sweden}

An interesting piece of case law governs WDT in Sweden. A cleaner was employed since 1986 in a nuclear plant. There were four unions in the plant and three of the unions agreed to allow testing of their members. Her union did not agree. In 1996, the union went to the Labour Court. The cleaner did not work in the nuclear plant itself but in an administrative block. The Court felt that working in a nuclear plant increased the need for WDT and ruled that the applicant must submit to a drug test but was not obliged to submit to an alcohol test.

The case was referred to European Court of Human Rights, which gave its judgement on 9 March 2004. It ruled that a very high level of security was needed in a nuclear plant as it is so safety critical. Drug use could jeopardize security. While the cleaner did not normally work in the safety critical area it would be impractical to differentiate employees and the application was rejected.

WDT in Sweden is increasing. Indeed, Volvo, a car manufacturer, tests at all of its facilities worldwide. New regulations in Sweden since 2010 have introduced random testing at airports. 
All employees working on the airside in airports are subject to random testing. Even incoming flights are subjects to random testing. That is unique in Europe. At Stockholm airport, the police perform about 1500 random tests per year airside. For many years, the air traffic controllers have also been drug tested randomly in Sweden.

\section{France}

The Ministry of Transport Act, 30 July, 2003 provides for a biological examination conducted by an occupational doctor to detect psychoactive substances for certain positions in the national railway system. In fact SNCF, the national rail company, tests but does not fire staff that test positive; they are merely redeployed to a non-safety critical post.

It usually depends on the inclination of the occupational physician whether to test or not: for example Renault, a car manufacturer, does, while Peugeot, another, does not.

\section{The Netherlands}

Pre-employment drug testing of all applicants is prohibited by law; however testing of the successful applicant is permitted in certain circumstances

The employee has the right of refusal and no negative conclusion can be formed from this.

\section{Italy}

An act came into effect in September 2008 which defined the safety critical situations in which workplace testing is mandatory and/or admissible. ${ }^{[12]}$ Two matrices, urine and hair, are collected. Forty to sixty millilitres of urine, which is quite a large amount, is (attempted to be) collected and is split three ways: two for screening and confirmation and a third that can be sent to another laboratory for an alternative analysis. Adherence to the regulations is more common in the north than the south of Italy. Random testing should be a surprise, but sometimes in the south of the country a few weeks' notice is given. Rehabilitation is a large part of this programme

\section{United Kingdom}

The Independent Inquiry into Drug Testing at Work did not recommend a national regulation on testing. Rather it recommended that the government should produce clear and definitive guidance on drug testing at work and particularly on the legal issues.

The UK did, however, set standards for testing in the railways (UKRailway Group standards GE/RT 8070 and RT/LS/P/051; superseded by GE/RT8070). ${ }^{[13]}$ These state that screening for drugs can take place randomly with at least $5 \%$ of staff being tested annually, and on a 'for cause' basis following an accident. Written notice of a random sample will not be given prior to sampling. Refusal to take a random alcohol and drugs test will result in a positive result being recorded.

\section{Ireland}

The Health and Safety at Work Act $2005^{[14]}$ requires that, in safety critical areas, an employee ensures that he or she is not under the influence of an intoxicant to the extent that he or she is in such a state as to endanger his or her own safety, health or welfare at work or that of any other person. 'Intoxicant' includes alcohol and drugs and any combination of drugs or of drugs and alcohol. The employee also, if reasonably required by his or her employer, must submit to any appropriate, reasonable, and proportionate tests, by or under the supervision of a registered medical practitioner.

It also puts the onus on the employer to ensure a safe workplace. The Health and Safety Authority had planned to issue further guidelines on implementation but has since changed its mind. The Attorney General (the senior lawyer who advises the government) has ruled that employers cannot enforce testing until legislation in place. This means that, at present, although the Act is there, the implementation is still not defined.

Similar to the UK, Ireland has brought in a railway act (The Railway Safety Act, 2005). It makes specific provision for random testing of safety critical workers. Intoxicant in this Act has the same definition as the Safety, Health and Welfare at Work Act, 2005. It defines safety critically workers as persons who perform safety critical tasks including driving a train, controlling the movement of persons on a train, or working in a maintenance capacity. This Act applies to safety critical workers on the rail and tramways.

One piece of case law has come from this Act: The driver of a tram screened positive for cannabis. The urine sample was then sent to a laboratory in another EU country. There was a delay in the transportation. The laboratory reported a level of $8.6 \mathrm{ng} / \mathrm{ml}$. Under EWDTS guidelines this should now be reported negative; however, the tram company maintained that they operated a policy of zero tolerance and the driver was fired. The driver's union took the case to the Labour Court. Despite many complicating factors, the Court upheld the union's case on the basis that while they claimed to work within the EWDTS guidelines, they did not do so. The driver was re-instated

\section{Conclusion}

In Europe, drug testing is about 15 years behind the USA and is usually implemented under a health and safety umbrella. More people join unions in Europe but, as WDT is a safety issue, the unions cannot usually object.

WDT is on a much smaller scale than in the USA and is likely to remain so. It is unregulated, with many ad hoc solutions and with alcohol testing often included. However, many European countries and companies are more adaptable to new methods, such as oral fluid testing and hair testing.

There is a growing interest and need for WDT, and a consequent need for regulation. Furthermore, the screening 1 process, both in the EU and the USA, is not able to detect the growing range of available intoxicants.

\section{Acknowledgements}

Much of the data on the individual countries was obtained from the European Monitoring Centre for Drugs and Drug Addiction (EMCDDA). ${ }^{[15]}$ Within its website is the European Legal Database on Drugs (ELDD), an online database of information on European drugs-related legislation for the member states and Norway.

\section{References}

[1] A. G. Verstraete, A. Pierce, Forensic Sci. Int. 2001, 121, 2.

[2] L. Hadfield, Drug Testing Anal. 2009, 1, 116.

[3] L. Hadfield, Drug Testing Anal. 2010, 2, 367. 
[4] L. Hadfield, Drug Testing Anal. 2010, 3, 269.

[5] EWDTS, European Laboratory Guidelines for Legally Defensible Workplace Drug Testing, Urine Drug Testing, 2002. Available at: www.ewdts.org/guidelines/EWDTSGuidelines.pdf [6 February 2012].

[6] EWDTS, European Laboratory Guidelines for Legally Defensible Workplace Drug Testing, Drug and Alcohol Testing in Hair. 2010. Available at: http://www.ewdts.org/guidelines/EWDTS\%20Guidelines\% 20Hair_Aug10.pdf [6 February 2012].

[7] EWDTS, European Laboratory Guidelines for Legally Defensible Workplace Drug Testing, Guidelines for Oral Fluid. 2010. Available at: http://www.ewdts.org/guidelines/EWDTS\%200ral\%20Fluid\%20Version 001\%2017MAR11.pdf [6 February 2012].

[8] The European Co-operation for Accreditation. Available at: www. european-accreditation.org
[9] Mandatory Guidelines for Federal Workplace Drug Testing Programs. 2008, United States Departement of Health and Human Services (HHS). Available at: www.workplace.samhsa.gov/Dtesting.html

[10] AS/NZS 4308:2008 - Procedures for specimen collection and the detection and quantitation of drugs of abuse in urine. 2008, Standards Australia. Available at: www.standards.org.au/

[11] The Convention for the Protection of Human Rights and Fundamental Freedoms. Available at: http://www.echr.coe.int/NR/rdonlyres/D5CC24A7DC13-4318-B457-5C9014916D7A/0/ENG_CONV.pdf [6 February 2012]

[12] Dipartimento Politiche Antidroga. Available at: www.coe.int/t/dg3/ pompidou/Source/Activities/Workdrug/Italy_doc.pdf

[13] UK Railway Group standards. Available at: www.rgsonline.co.uk

[14] The Health and Safety at Work Act 2005. Available at: www.hsa.ie

[15] The European Monitoring Centre for Drugs and Drug Addiction. Available at: www.emcdda.europa.eu 